[13] Mukaka M., (2012); A Guide to Appropriate Use of Correlation Coefficient in Medical Research, Malawi Med. J., 24 (3), 69-71

[14] Wang T., Zhang S. (2011); Study on Linear Correlation Coefficient and Nonlinear Correlation Coefficient in Mathematical Statistics, Studies in Mathematical Sciences, 3 (1), 58-63, DOI: 10.3968/j.sms.1923845220110301.4Z483

[15] Smith R. (2015); A Mutual Information Approach to Calculating Nonlinearity, Stat, 4, 291-303, DOI: 10.100X/sta.0000

[16] Guerard J. (2013); Introduction to Financial Forecasting in Investment Analysis, Springer, New York, DOI:10.1007/978-1-4614-5239-3

[17] Trajković S., Lutovac S., Katona O. (2009); Study of Seismic and Air Impacts on the Surrounding Building Structures as the Result of Blasting at the Open Pit "Drenovac" Near Mionica, Faculty of Mining and Geology, Belgrade, 34(A), 15-51(B) (in Serbian).

https://doi.org/10.31713/m1112

\title{
BITUMEN EXTRACTION TECHNOLOGY FROM BITUMINOUS SAND DEPOSITS
}

Yelchenko-Lobovska A.S.

National University «Yuri Kondratyuk Poltava Polytechnic»,

PhD Student, Ukraine

\section{Lavryk I.O.}

National University «Yuri Kondratyuk Poltava Polytechnic»,

PhD Student, Ukraine

Liashenko A.V.

National University «Yuri Kondratyuk Poltava Polytechnic», senior lecturer, Ukraine

Pedchenko L.O.

National University «Yuri Kondratyuk Poltava Polytechnic», $\mathrm{PhD}$, Ukraine

\section{Pedchenko M.M.}

National University «Yuri Kondratyuk Poltava Polytechnic», $\mathrm{PhD}$, Ukraine

\footnotetext{
Abstract

Today considerable experience in the development of tar sands is accumulated. However, well-known mining technologies do not cover the entire depth range of natural bitumen deposits. In addition, there are significant energy-intensive technol-
} 
ogies and negative environmental impacts. In view of this, the purpose of this work is to improve the method of extracting natural bitumen in site for a deposit interval of 75-200 $\mathrm{m}$ and to substantiate the basic technological scheme of this method. The proposed method of extracting bitumen from poorly cemented reservoirs in the depth range of $50-400 \mathrm{~m}$ provides: creation of artificial production; the transfer of the rock into the water mixture composition under the action of high pressure jets of a heated mixture of water, a hydrocarbon solvent and a flotation agent; separation from the rock and concentration of bitumen in the production as a result of its heating, dissolution and flotation; selection of depleted bitum slurry from the production by gas lift. The proposed method of extracting bitumen is the transfer of the rock at the its occurrence site to the suspension condition on the excavation created by the hydraulic production method, separation and concentration of bitumen by dissolving it with a heated hydrocarbon solvent and a flotation agent (hydrocarbon reagents) and extraction in composition of the depleted rock slurry to the surface by the gas lift method. As the preliminary calculations show, the proposed method will allow the efficient extraction of bitumen and highly viscous oil from weakly cemented reservoirs in the depth range of 50-400 $\mathrm{m}$. Also, the proposed technology creates the preconditions for the development of oil sands at a depth of 75-200 m since there is currently no effective technology for the interval. In addition, it can significantly reduce energy costs, environmental pollution and greenhouse gas emissions.

\section{Introduction}

The depletion of traditional deposits and the rise in energy prices have led to considerable interest in exploring unconventional hydrocarbon fields. Heavy oil and natural bitumen are one of the strategic hydrocarbon reserves for oil companies around the world. Their reserves are many times higher than those of traditional oil and gas.

Approximately 1.7 trillion barrels of crude bitumen are in the oil sands [1,2] but predicts that only $19 \%$ of this total (315 billion barrels), will ultimately be recovered. A smaller amount, 174 billion barrels, could be recovered using today's technology and under current and anticipated economic conditions [1]. (For comparison, crude oil reserves in Saudi Arabia are estimated at 264 billion barrels.)

The development of natural bitumen reserves is being successfully implemented in Canada, the USA and other countries in the world [3].

Thus, oil sands production in Alberta increased from about 1 million barrels/day in 2004 to 2.4 million barrels/day in 2014. This is equivalent to an annual increase of $8 \%$.

All geological preconditions for the formation of large industrial clusters of high-viscosity oil and natural bitumen are in Ukraine as 
well. However, targeted search and exploration work to identify them in Ukraine is not being conducted. All known deposits were discovered incidentally during oil and gas exploration [4].

Bituminous sands contain 9-13\% bitumen, 3-7\% water and 80$85 \%$ rock. Small particles, preferably clay, with a diameter of less than 44 microns are from $15 \%$ to $30 \%$ of the rock. The task is to separate the bitumen not only from the sand grains, but also particles of micron and submicron size clay.

In addition, bituminous oil has a high density $\left(0.965-1.22 \mathrm{~g} / \mathrm{cm}^{3}\right)$ and anomalous viscosity (over $104 \mathrm{MPa} \cdot \mathrm{s}$ ). Sulfur and metals, especially vanadium and nickel in concentrations comparable to their content in ore deposits, are also part of it.

Thus, natural bitumen is significantly different from traditional oil in chemical composition, physicochemical properties, the degree of interaction with the host rocks and the nature of the saturation of the pore environment. Therefore, the methods and approaches used in the extraction of traditional oil cannot be directly implemented for the development of high-viscosity oil deposits and natural bitumen [4].

In this regard, a number of methods for the bitumen extraction from tar sands have been developed. A number of methods are receiving refinement and improvement.

\section{Methods of oil sands development}

Oil sands are mainly developed in two ways: the extraction of bitumen by the quarry method and the methods of its extraction in site [5]. The choice of method depends mainly on the depth of the reservoir. Deposits at depths of up to $50 \mathrm{~m}$ and subject to surface mining account for about $20 \%$ of Canada's bitumen deposits. The remaining $80 \%$ of the oil sands that can be mined at the site.

A quarrary method involves two major steps: the removal of the rock from the quarry and the extraction of bitumen in industrial installations. After the rock is extracted, bitumen is separated from the sand by a process of hot water extraction, patented in 1928 by Dr. Carl Clark (bitumen is separated from sand and clay particles by a combination of mechanical energy, heat, and the presence of surfactants). Currently modifications of this method are applied [6].

Pieces of petroleum sandy ore are ground and mixed with warm water containing $\mathrm{NaOH}$ to form an aqueous slurry at the mining 
sites. The slurry is then conditioned at elevated temperatures to help release bitumen. Traditionally, extraction drums are used to extract bitumen at $80{ }^{\circ} \mathrm{C}$. Recently, pipelines leading to the primary separation unit at $35-50^{\circ} \mathrm{C}$ have been used to facilitate separation.

In hydraulic pipelines and drums, the pieces of rock left in the slurry are displaced and reduced in size. In drums or in hydraulic pipelines, bitumen is «released» from the grains of sand. Phase separation is enhanced by mechanical displacement and breaking pressure. At a temperature of $35-50{ }^{\circ} \mathrm{C}$ and the $\mathrm{pH}$ of the suspension within 8-8.5 bitumen is separated, forming droplets that are released from the grains with stirring of the suspension.

Because bitumen and water have similar densities, the flotation method is used to separate them. For this, bitumen is gradually aerated at a rate of about $30 \%$ by volume of gas to the mixture volume. However, it is very difficult to organize the supply of the optimum amount of air for quality aeration and to avoid excessive air supply [5].

In [7] it was shown that the aeration stage is the most critical and this has the effect of bitumen loss.

Thus, during conditioning, the liquid suspension is aerated and ideally the bitumen is separated from the sand, attached and distributed to air bubbles. The bituminous foam collected in the gravity separation vessel contains about $10 \%$ solids and $30 \%$ water. The foam air bubbles are easily removed by heating or gravity drainage, but the viscous bitumen is not easily cleaned of small clay particles and drops water emulsified. Dilution of bitumen with a solvent reduces its viscosity and density and accelerates the settle of denser solids. However, emulsified droplets of water and clay particles have tiny diameters, so they settle very slowly [8-9].

The process is carried out using inclined plates of sedimentation tanks, cyclones and centrifuges. For this operation, Syncrude and Suncor use a light fraction of oil (mainly hexane) as the solvent for foaming. When the solvent is used in a sufficiently high amount, the bitumen asphaltene is partially precipitated. This results in the formation of composite aggregates that catche water and solids from diluted bitumen foam. This method significantly improves the gravitational separation, thus eliminating the need for cyclones or centrifuges.

The successful application of water-based technologies for the extraction of bitumen from the Athabasca oil sands lies in the key fact 
that the sand in the oil sands is hydrophilic. Also, it is believed that a thin layer of water surrounds the individual grains of sand (about 10 $\mathrm{nm}$ thick), separating them from bitumen [10]. The most characteristic feature of the Alberta oil sands is that the grains are moist or hydrophilic. This hydrophilic tendency of the sands is successful because the process of extracting bitumen with hot water would not work if the grains were not moistened.

It is assumed that the water film is stabilized by electrostatic forces resulting from the formation of a double electric layer at the boundary of the phase separation of «oil - water» and «water - sand» [11-14].

Quartz sand absorbs most of the bitumen and water mixture, forming a continuous phase. The water film separates bitumen from sandy and clay surfaces.

Thus, the removal of bitumen from the oil sands using the processes of water-based extraction includes the following steps:

- grinding of rock that occurs in bunkers or hydraulic pipelines in the process of heating its surface and gradual erosion;

- separation of bitumen from sand grains. (The speed of this step depends on the balance between the forces of bitumen separation the from the sand grain and the force of attraction (sticking) of the bitumen to these grains.) The processes of this stage are affected by the rate of heat transfer, mechanical mixing, chemical additives and interfacial properties;

- the bitumen droplet released from the sand is attached to the air bubble. Depending on the process temperature, the bitumen either attaches to the air bubble at a low temperature process $\left(<35^{\circ} \mathrm{C}\right)$ or absorbs the bubble in «hot» $\left(75-80{ }^{\circ} \mathrm{C}\right)$ or «warm» (about $45^{\circ} \mathrm{C}$ ) processes. As a result of aeration, the bitumen floats to the top of the gravity separation vessel. As a result, a layer of bitumen foam is formed.

For any production method, the extracted bitumen for quality improvement is subjected to primary processing for synthetic oil. In this case, residual of the rock (mainly clay fraction) and water are also removed from the bitumen. (Before distillation, the diluted bitumen product typically contains approximately $2 \%$ water and $0.5 \%$ fine solids.)

This processing is similar to ordinary crude oil treatment using cracking and hydrotreating processes. The synthetic crude oil is then sent to an oil refinery for further physical and chemical processing. 
Unfortunately, the quarrying method cannot be used for deeper tar sands. In this case, in-situ well production technologies are applied. In this case, methods that minimize their viscosity is the most rational [15].

Among such methods, thermal and thermochemical occupy a special place. These include different combinations of steam or solvent injection through horizontal or vertical wells. Currently, two main types of in-site methods are made and widely implemented: Cyclic Steam Stimulation (CSS) and Steam-Assisted Gravity Drainage (SAGD) [16].

Both methods include the injection of hot steam into a reservoir for heating oil sands in order to reduce the viscosity of the bitumen and to stimulate its production. The CSS method was the first to be used in the production of bitumen in site. It includes the injection of water vapor into the well at a temperature of $250{ }^{\circ} \mathrm{C}$ to $400{ }^{\circ} \mathrm{C}$. Water vapor advancing the layer heats the bitumen, reducing its viscosity. The wells are allowed to settle for several days or weeks and then the hot oil mixed with condensed water is pumped out for weeks or months. Then the method is repeated. However, in addition to the high cost of pumping water vapor, the CSS method generally results in bitumen extraction not exceeding 20-25\%.

Another in-site method (currently most widely used) is SteamAssisted Gravity Drainage. The method includes the drilling of two horizontal wells - one at the bottom of the formation and the other five meters above it. Water vapor is injected into the upper well, melting the bitumen, which then flows into the lower well.

The degree of water conversion to steam is about $75 \%$, i.e. $1 \mathrm{~kg}$ of feed water generates $0.75 \mathrm{~kg}$ of steam, and $0.25 \mathrm{~kg}$ remains in the liquid form [17].

The process of steam gravity begins with the stage of preheating, during which (several months) the steam is circulated in both wells. However, due to the conductive heat transfer, the zone of the reservoir between the extraction and injection wells is heated, the bitumen viscosity in this zone is reduced and thus the hydrodynamic connection between the wells is provided. At the main stage of extraction, steam is already pumped into the injection well.

The resulting liquid oil mixed with condensed water vapor is pumped to the surface. The level of bitumen extraction by the SAGD method reaches 40-60 percent. However, this method is most effective for the extraction of oil sands located at a depth of more than $200 \mathrm{~m} \mathrm{[18].}$ 
The above methods have many problems related to the level of costs and the negative impact on the environment. For example, the use of large amounts of water vapor requires high energy consumption and the use (and placement) of large amounts of water. Currently, the extraction and processing of tar sands requires several barrels of water per barrel of oil obtained [19].

Open field development and further processing results in significant sand volumes that is not fully cleared. It requires further processing before being returned to the environment. In addition, the use of large quantities of caustic soda for extraction by the quarry method improves the stability of fine clay particles in waste, the removal which is a major problem of the influence on the environmental.

Calculations show that energy consumption to increase the temperature of 1 ton of oil sand by $1{ }^{\circ} \mathrm{C}$ is about $5 \mathrm{MJ}$. Such an energyintensive process inevitably releases greenhouse gases that pose a threat to the environment. Therefore, for the development of natural bitumen deposits with the achievement of acceptable values of extraction coefficients, new methods are needed that are superior to the efficiency of traditional steam-boiling technologies.

Solvent extraction is one possible alternative. Here, the introduction of thermal energy at the beginning of the extraction process can be minimized (the process can be carried out even at ambient temperature) by adding solvents that reduce the viscosity of the bitumen.

In this regard, methods the bitumen extraction by the solvent (eg, VAPEX, N-Solv) are being developed.

Thus, in the VAPEX - VAPor EXtraction method (using solvents in a vaporous state) a mixture of solvents (propane, butane, oil and methane) is pumped into the reservoir in the form of steam into the upper horizontal well (Fig. 1). The solvent is mixed with bitumen to reduce its viscosity.

The extraction process is carried out through the lower horizontal well. The process uses no water and produces no $\mathrm{CO}_{2}$. But the project has not yet found widespread implementation as a number of important technical issues have not been resolved (the process of dissolution is very slow). 


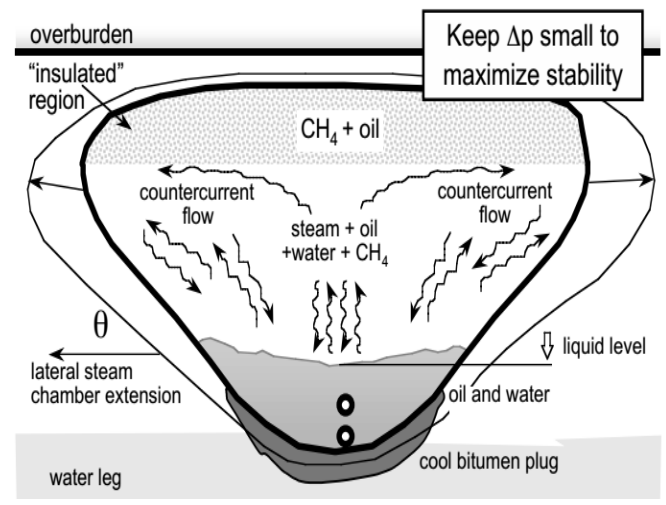

Fig. 1. Basic elements of SAGD (\& VAPEX)

New technology of N-Solv (Fig. 2), includes pumping into the reservoir of solvent (propane) heated to a temperature of $\sim 50{ }^{\circ} \mathrm{C}$. Propane dissolves bitumen, its most heavy components remain underground. Lighter oil and solvent, which is able to restore, are lifted to the surface. In addition, the mass is less viscous than in the traditional underground method, so it can be immediately transported by pipeline.

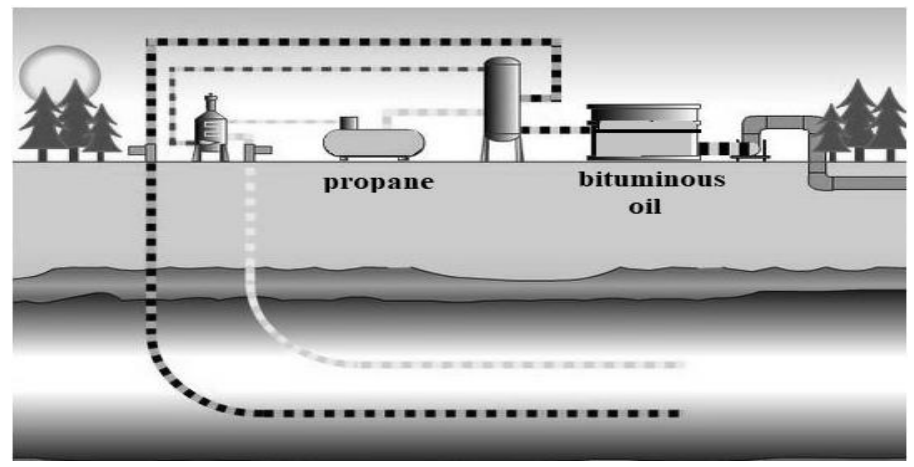

Fig. 2. Technology of oil extraction from tar sands

(N-Solv technology)

Moreover, the improvement of the N-solv technology itself by heating the solvent, as well as cleaning it from methane admixture made it possible to significantly increase the efficiency of the pro- 
cess. (It was found that the methane presence in the formation significantly worses the process of heat exchange at the interface of solvent - bitumen).

As a result, greenhouse gas emissions are reduced by $80 \%$ compared to traditional methods of production. In addition, the heavy admixtures present in bitumen - such as sulfur, asphaltenes, heavy metals and the heaviest hydrocarbon fractions - remain underground.

However, known methods that include the injection of water vapor or hydrocarbon solvents have a significant disadvantage associated with the heterogeneity of the rock productive layers. This inevitably leads to their breaking in the production wells and the need to apply flow diversion technologies (blocking gels, sediment-forming compositions).

Because of this, most horizontal sections of SAGD wells are laid at a depth of more than $200 \mathrm{~m}$ (due to the danger of the agent breaking into the surface). In the article [18] analyzes 28 SAGD wells. They are drilled in the range $212-425 \mathrm{~m}$, with an average of $303 \mathrm{~m}$.

As the lower boundary of the quarry development is $75 \mathrm{~m}$ depth, there is a considerable interval of natural bitumen bedding (at least $125 \mathrm{~m}$ capacity (in the range $75-200 \mathrm{~m}$ ) for which there is no acceptable extraction technology.

Thus, today there is a need for efficient, safe and economical ways of removing bitumen from tar sands. In addition, an important task is to develop an effective method for the deposit interval of tar sands.

\section{Justification of technology parameters}

An analysis of the accumulated experience in the development of tar sands showed that one of the ways in-site technology development (for this interval) could be the technology proposed by the authors. It would allow processes to be carried out directly in the area of the bituminous rock occurrence. The processes are similar to those occurring in above-ground technological equipments (bituminous sand processing) by the Clark method [6].

Moreover, the area of implementation of these processes, considering the need to reduce energy consumption and environmental impact, should be local, controlled and as isolated as possible. 
The latter condition, taking into account the properties of the bituminous rock, can be fulfilled provided that the pressure in the limited working area is not at the level of formation.

These requirements, in our opinion, can be fulfilled provided the consistent implementation by the technology of the following operations:

- formation in the productive layer of mountain excavation, which will be an area for geotechnological processes, according to the Clark method [6];

- the bring of the necessary amount of heat and reagents for reduce the bitumen viscosity and its separation from the rock;

- formation of conditions for efficient bitumen extraction and its extraction in the most concentrated form.

In addition, the technology must have minimal impact on the environment, provide maximum heat recovery, have a minimum period from the beginning of the project to the receipt of products and output to the design capacity.

Analysis of known technological solutions today showed that the above requirements can correspond the technology developed on the basis of elements of well production technology [20].

This technology includes the opening of a well, the rock's breaching at the place of its occurrence with the help of a jet stream, the transfer of the rock into the hydraulic mixture composition and extraction to the surface [20].

The mechanism of hydraulic rocks fracturing is a complex process caused by the simultaneous action of a number of factors. These include normal and tangential stresses when the jet influence to an array, dynamic shock action, filtration pressure, abrasive action, etc. [21].

An added advantage of the technology is that it allows the mining of disconnected ore bodies in flooded wells in high water inflows, as well as under water and offshore.

However, the rapid decay of the jet energy occurs in the conditions of bottom well flooded. This requires the use of hosepipes or telescopic monitors that lengthen as the motion of the bottom well. As a result, the extraction of the rock mass and the unit construction are complicated, as well as the risk of the roof collapse and clogging of equipment.Therefore, this technology requires improvement and adaptation to the features of the tar sands deposits development. 
Significant susceptibility to bituminous sand disintegration (especially after reducing the bitumen viscosity as resultate heating or solvent action) is a positive factor to the protection of this method.

Taking into account the above requirements for bitumen and high-viscosity oil extraction technology at the site of their precipitation, as well as the features (and disadvantages) of the technology well hydraulic extraction of the minerals in works [22, 23], a method (Fig. 3) is proposed, which includes:

- disclosure of the productive layer horizontal well 8 heated working fluid - water with surfactants;

- transfer of the rock (from the bottom of the well) to the slurry as a result of the action of high-pressure working fluid streams (stream III) $(5-20 \mathrm{MPa})$ at a temperature above $100{ }^{\circ} \mathrm{C}$ (stream III). Moreover, the rods of hydromonitors 7 with nozzles in the working position occupy perpendicular to the axis of the well position. In the process, they rotate around the well axis and gradually move along in the direction of contact with the fracture front. Mountain excavation gradually forms, which develops in the direction of the wellhead;

- increment of the destructive action of the working fluid jets due to the abrasive action of the rock 2 particles, which are captured by the hydromonitore jets 7 together with part of the pulp in the interval from the nozzle slice to the front of destruction;

- carry into the excavation with the working fluid flow of thermal energy to reduce the bitumen viscosity;

- the gravitational compartment at some distance beyond the hydromonitors 7 (where turbulent mixing is extinguished) from the formed pulp of the main part of the rock 2, (except the clay fraction). As a result, the pulp is enriched with bitumen and pushed back to the vaulted excavation;

- withdrawal from the production of bitumen-enriched pulp (stream II) through the slurry tank 5, located in the vaulted part of the production to the separator 12;

- separation from the pulp in the separator 12 of the solid phase remainder (stream $\mathbf{I})$;

- the selection of the bitumen concentrate (stream $\boldsymbol{I V}$ ) and sending it for further processing. 


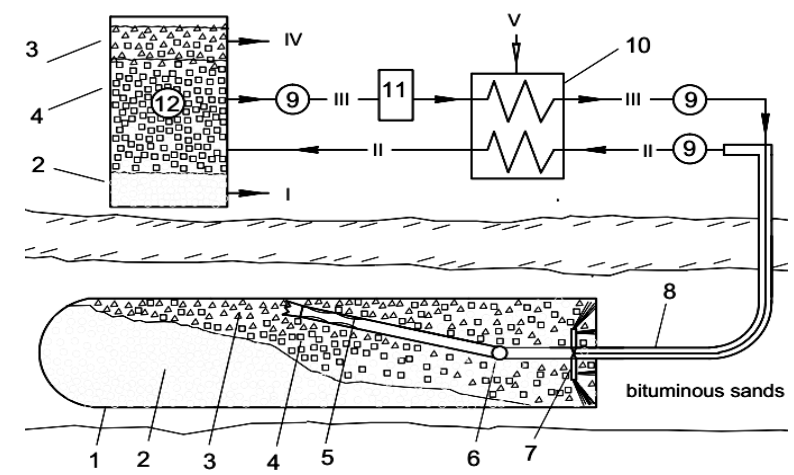

Fig. 3. Scheme of the bitumen's extracting method from the tar sands deposits: 1 production; 2 - sediment of sand; 3 - pulp enriched with bitumen; 4 - water with a clay fraction; 5 - a shank with a chisel and a pulp gathering; 6 - the hinge; 7 - hydromonitor device; 8 - well; 9 - pump; 10 - block of heating; 11 - a block of partial separation of the solid phase; 12 - separator; streams: I - sand precipitate; II - pulp enriched with bitumen; III - clay solution; IV - bitumen; V - a coolant

It is also assumed that outside the hydraulic system where the pressure corresponds to a reservoir, the level of superheating of the fluid in the fracture zone will be sufficient to boil it. The formation of water vapor bubbles in the rock pores the will increase the process of its disintegration. Then, in the resulting water mixture, the bitumen drops are attached to the bubbles. Similarly to the processes carried out in the extraction plants, the process of bitumen flotation to its vaulted will take place in the mountain excavation.

However, the technology proposed in [22, 23] is based on thermal processes of bitumen extraction and therefore cannot be perfect in terms of energy efficiency, environmental impact through $\mathrm{CO}_{2}$ emissions. Therefore, there are reserves for its improvement and competitiveness.

Heating (even in the localized zone) of the productive layer, based on the bitumen low content, heat capacity and thermal conductivity of the rock, without the prospect of heat recovery is unjustified. 
It is known that a positive result can be achieved by using solvent bitumen to reduce the viscosity. (The positive experience of moderate heating (eg up to $50{ }^{\circ} \mathrm{C}, \mathrm{N}$-Solv method) should also be used). It is also expedient to use the liquid solvent as part of the working fluid of the hydromonitors when making it into excavation.

In addition, instead of the bitumen flotation with water vapor bubbles, it should be provided to introduce into the excavation a flotation agent which, under thermobaric conditions of production, was in a gaseous state and in the supply line in a liquid state. (Therefore, it was fed into the well of the working fluid for monitors).

Also, to maximize bitumen extraction and reduce solvent losses, the following should be considered.

It is estimated that about $70-80 \%$ of the rock (mainly sand), based on the composition of bituminous sand, will separate as a result of gravitational deposition from the pulp in the production. As a result, mountain excavation approximately $4 / 5$ of the cross section will be filled with sediment. Its porosity will be about $30 \%$. On this basis, ideally the process should be organized in such a way that the pore space of the sediment was filled with a slurry of water and clay fraction of the rock. In this case, all the bitumen, together with the flotation agent, will be displaced from the sludge to the vaulted excavation.

After taking into account (and agreeing) the above positions, a method (geotechnology) and a schematic diagram (Fig. 4) of «cold» hydropower in-site bitumen from deposits located at a depth of 50 to $400 \mathrm{~m}$ are proposed.

The method provides:

- disclosure the reservoir with horizontal wells; 


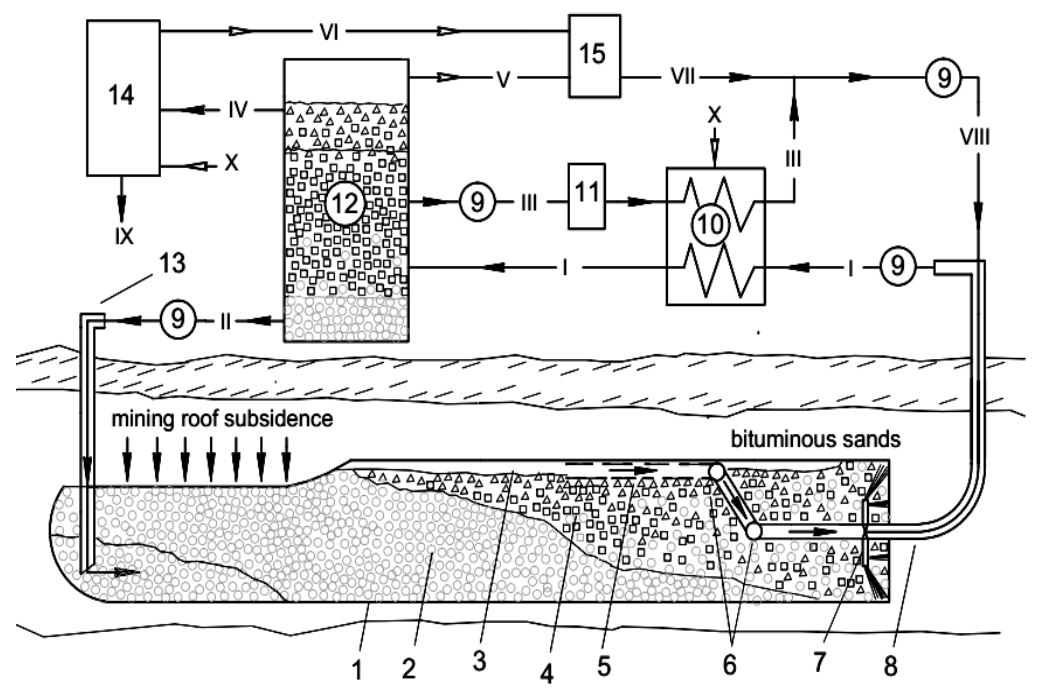

Fig. 4. Schematic diagram of an improved method of extracting bitumen from tar sands: 1 excavation; 2 - sediment of the rock; 3 - gas cap; 4 - water mixture, enriched with bitumen; 5 - intake device; 6 - swivel connection; 7 -hydromonitors; 8 - horizontal section of the well; 9 - pump; 10 - the heater; 11 - a filter; 12 - separator; 13 - injection well; 14 - evaporation column; 15 - the liquefaction unit; flows: I - mixture of bitumen, solvent, water, clay fraction of rock and flotation agent; II - rocks; III - water; IV - a mixture of bitumen, solvent and flotation agent; V - a gaseous flotation agent; VI - gaseous solvent and flotation agent; VII liquefied solvent and flotation agent; VIII - a mixture of water, solvent and flotation agent; IX - bitumen; $\mathbf{X}$ - supply of thermal energy

- transfer of the rock (starting from the bottom well) to the slurry as a result of the action of jets working fluid (stream VIII) of high pressure $(5-20 \mathrm{MPa})$ at a temperature of about $50{ }^{\circ} \mathrm{C}$. Moreover, the rods of hydraulic monitors 7 with nozzles in the working position occupy perpendicular to the axis of the well position. In the process, they rotate around the well axis and gradually move in the direction of contact with the fracture front. Mountain excavation (mining) is gradually forming, which develops in the direction of the wellhead. Disintegration of the rock of the productive layer is carried out by high-pressure working fluid jets, which include water, flotation agent and bitumen solvent. In this case, the flotation agent in the thermobaric conditions of the flow line of the working fluid and until the nozzles slice hydromonitors is in a condensed state, and in the 
production - evaporates. After that, its part in the form of bubbles is attached to the bitumen drops and the rest - accumulates in the vault;

- magnification of the destructive action of the working fluid jets due to the abrasive action of the particles of the rock 2, which are captured by the hydromonitor jets 7 together with part of the pulp in the interval from the nozzle slice to the front of destruction;

- the separation of natural bitumen from the rock occurs as a result of reducing its viscosity under the action of solvent;

- at some distance along the hydromonitors 7 (where turbulent mixing goes off) the gravitational separation of the hydraulic mixture into the sediment layer (rocks 2 and water in the pores), the gas cap 3 of the flotation agent vapor in the vault, and the target product layer between them - hydraulic mixture enriched with rhe bitumen 4 (bitumen, solvent, water, clay fraction of rock and flotation agent);

- selection from the excavation excavation (stream $I$ ) of hydraulic mixture enriched with bitumen 4 is carried out by gas lift method due to the excess pressure formed by the working fluid (stream VIII) and the flotation agent in the gas cap 3;

- the selection of the target product (stream $\boldsymbol{I}$ ) to the separator 12 is carried out through the intake device 5, which in the working position floats to the pulp concentrate area and its end, to capture gas to form the gas lift effect, is located on the border of the pulp - gas cap. In this case, the intensity of selection of the enriched pulp will be regulated by the flow rate of the hydromonitors working fluid and its composition;

- separation in the separator 12 selected from the production of the hydraulic mixture to the working fluid (stream $\boldsymbol{I I I}$ ), which under pressure is fed to the hydraulic monitors 7, a bitumen mixture, flotation agent and solvent (stream $\boldsymbol{I} \boldsymbol{V}$ ) and rock (stream $\boldsymbol{I}$ ).

As a flotation agent propane gas mixture is proposed to be used. Moreover, the ratio of these components in the mixture will depend on the technological parameters of the particular object of development (depth of occurrence and temperature in the production).

A wide fraction of light hydrocarbons obtained from the destruction of the produced bitumen in the process of its preliminary preparation is proposed to be used as a solvent. Its component 
composition will also be determined by the specific conditions of the development object.

The mixture of bitumen, solvent and flotation agent (stream $\boldsymbol{I V}$ ) in the evaporator 14 is divided into bitumen (stream $\boldsymbol{I X}$ ) and a pair of flotation agent and solvent (stream $\boldsymbol{V I}$ ). Separated in the separator 12 flotation agent (stream $\boldsymbol{V}$ ) and vapor mixture of flotation agent and solvent from the evaporation column 14 (stream $\boldsymbol{V I}$ ) are liquefied in block 15 . The water from the separator 12 (stream $\boldsymbol{I I I}$ ), if necessary, is additional purified from the clay admixtures in the filter 11 , heated to a temperature of $50-60{ }^{\circ} \mathrm{C}$, connects with the flow of liquefied solvent and flotation agent (stream $\boldsymbol{V I I I}$ ) and high pressure pumps 9 is fed to the hydromonitors (as a working fluid). Water, flotation agent and solvent to the hydromonitors (given the small diameter of the pipeline, high pressure and flow rate) come in a enough dispersed and homogeneous mixture.

The precipitate from the separator 12 and other waste through the injection well 13 in the form of flow $\boldsymbol{I I}$ is pumped into the lower part of the spent excavation (production) interval (to prevent a breakthrough into the production area).

One of the parameters that is proposed to take into account when choosing the diameter of the formed excavation is its mechanical resistance to fracture. The best option will be when in the interval of the working area the vault will be stable. But at some distance, the production will gradually deform, while pushing pulp and gas cap enriched with bitumen to the working zone.

The pressure in excavation (production) 1 will be insignificant and will exceed the hydrostatic only by the amount necessary for the organization of the gas-lift of the hydraulic mixture. Therefore, the pulp breakthrough to the surface is excluded. Therefore, there will be no limitations on the characteristics of the rock in the productive layer roof.

Based on the processes that will take place in the production, the bitumen extraction coefficient of this technology can compete with the coefficient for the career mode. The method will allow for easy extraction of bitumen (highly viscous oil) at the site at any depth, starting from the minimum. 
The profitability of in-situ oil sands development technologies is primarily determined by the bitumen extraction coefficient and specific energy consumption. With the recent fall in oil prices, the development of oil sands has faced difficulties. However, with the recent fall in oil prices, the development of oil sands has faced difficulties. In this regard, the presented technology has a number of advantages. It will be the most energy efficient because it does not provide a period of long pre-heating of the rock. In addition, thermal energy is introduced directly into the zone of the rock destruction. As a result, energy losses to the surrounding rock will be minimal. It is assumed that the bitumen extraction coefficient is at the level of the quarry method.

\section{Conclusions}

1. A method of extracting bitumen from weakly cemented reservoirs is proposed and scientifically substantiated, which includes: formation of artificial excavation (production); the transfer of the rock into the composition of the water mixture under the action of high pressure jets of a heated mixture of water, a hydrocarbon solvent and a flotation agent; separation from the rock and concentration of bitumen in production as a result of its heating, dissolution and flotation; selection of the depleted by the rock of suspension from excavation (production) due the gas-lift method.

2. The proposed method allows the extraction of bitumen from weakly cemented reservoirs at the place of occurrence for a depth interval of 75-400 m.

3. The proposed method does not require preliminary drainage of the site, and therefore shortens the start of production.

4. The pressure in the production will be around to the hydrostatic one, so the pulp breakthrough to the surface is excluded. There will also be no limitations on the characteristics of the rock in the roof of the productive formation.

5. The duration of preparatory operations will be insignificant. The selection of products will begin almost immediately after the inflow of the working fluid on the hydraulic monitors. 
References

1. Alberta Energy \& Utilities Board, Alberta's Reserves 2004 and Supply/Demand Outlook/Overview (2005), Statistical Series (ST) 2005-98, 2.

2. Kraemer, D., Bajpayee, A, Muto, A., Berube, V., \& Chiesa, M. (2009). Solar assisted method for recovery of bitumen from oil sand. Appl Energy, 86, 1437-41.

3. Lukin O.Y. (2008). Vuhkevodnevyi potentsial nadr Ukrainy ta osnovni napriamky yoho osvoyennia. Visnyk Nationalnoi Akademii Nauk Ukrainy, (4), 5667.

4. Stebel'ska H.Y. (2015). Heolohichni umovy rozvidky ta rozrobky pokladiv vysokoviazkykh naft ta pryrodnyh bitumiv. Visnyk Kharkivs'koho natsional'noho universytetu, (1157), 53-57.

5. Masliyah1, J., Zhou, Z., Xu, Z., Czarnecki, J., \& Hamza, H. (2004). Understanding Water-Based Bitumen Extraction from Athabasca Oil Sands. Canadian Journal of Chemical Engineering, 82, 628-654.

6. Kasperski, K.L. (2001). Review of research on aqueous extraction of bitumen from mined oil sands. Report.CANMET Energy Technology Centre, Natural Resources Canada, Devon, report CWRC 01-17 (CF).

7. Liu, J., Xu, Z., \& Masliyah, J. (2005). Processability of Oil Sand Ores in Alberta. Energy Fuels, 19(5), 2056-2063. https://doi.org/10.1021/ef050091r

8. Romanova, U.G., Valinasab, M., Stasiuk, E.N., Yarranton, H.W., Schramm, L.L., \& Shelfantook, W.E. (2006). The Effect of Oil Sands Bitumen Extraction Conditions on Froth Treatment Performance. Journal of Canadian Petroleum Technology, 45(9), 36-45. https://doi.org/10.2118/06-09-03

9. Schramm, L.L., Stasiuk, E.N., Yarranton, H., Maini, B.B., \& Shelfantook, B. (2003). Temperature Effects in the Conditioning and Flotation of Bitumen From Oil Sands in Terms of Oil Recovery and Physical Properties. Journal of Canadian Petroleum Technology, 42(8), 55-61. https://doi.org/10.2118/03-08-05

10. Czarnecki, J., Radoev, B., Schramm, L.L., \& Slavchev, R. (2005). On the nature of Athabasca oil sands. Adv. Colloid Interface Sci., 114-115, 53-60. https://doi.org/10.1016/j.cis.2004.09.009.

11. Czarnecki, J., \& Moran, K. (2005). On the Stabilization Mechanism of Water-In-Oil Emulsions in Petroleum Systems. Energy Fuels 19(5), 2074-2079. https://doi.org/10.1021/ef0501400

12. Czarnecki, J., Moran, K., \& Yang, X. (2007). On the "Rag Layer" and Diluted Bitumen Froth Dewatering. Can J Chem Eng 85(5), 748-755. https://doi.org/10.1002/cjce.5450850520

13. Taylor, S.E. (2018). Interfacial Chemistry in Steam-Based Thermal Recovery of Oil Sands Bitumen with Emphasis on Steam-Assisted Gravity Drainage 
and the Role of Chemical Additives Colloids Interfaces, 2, 16; https://doi.org/10.3390/colloids2020016

14. Drelich, J. (2008). Wetting phenomena in oil sand systems and their impact on the water-based bitumen extraction process. Mining, Metallurgy \& Exploration, 25, 1-12. https://doi.org/10.1007/BF03403379

15. Shah, A., Fishwick, R., Wood, J., Leeke, G., Rigby, S., \& Greaves M. (2020). A review of novel techniques for heavy oil and bitumen extraction and

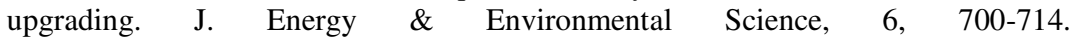
ttps://doi.org/10.1039/B918960B

16. Lazzaroni, E.F., Elsholkami, M., Arbiv, I., Martelli, E., Elkamela, A., \& Flowler, M. (2016). Energy infrastructure modeling for the oil sands industry: current situation. Appl Energy, 181, 435-445. https://doi.org/10.1016/j.apenergy. 2016.08.072

17. Hofmann, H., Babadagli, T., \& Zimmermann, G. (2014). Hot water generation for oil sands processing from enhanced geothermal system: process simulation for different hydraulic fracturing scenarios. Appl Energy, 113, 524-547. https://doi.org/10.1016/j.apenergy.2013.07.060

18. Rui, Z., Wang, X., Zhang, Z., Lu, J., Chen, G., Zhou, X., \& Patil S. (2018). A realistic and integrated model for evaluating oil sands development with Steam Assisted Gravity Drainage technology in Canada. Applied Energy. 213, 7691. https://doi.org/10.1016/j.apenergy.2018.01.015

19. Allen, E.W. (2008). Process water treatment in Canada's oil sands industry: I. Target pollutants and treatment objectives. Journal of Environmental Engineering and Science, 7(2), 123-138. https://doi.org/10.1139/S07-038

20. Bondarchuk, I.B., \& Shenderova, I.V. (2015). Classification of hydraulic borehole mining technological processes during pay zone development. IOP Conf. Ser.: Earth Environ. Sci. 24 012004. https://doi.org/10.1088/1755-1315/24/1/012004

21. Rehbinder, G. (1980). A Theory about Cutting Rock with Water Jet. Rock Mechanics, 12(3-4), 247-257. http://dx.doi.org/10.1007/bf01251028

22. Pedchenko, L., Pedchenko, N., Manhura, A., \& Pedchenko, M. (2019). Development of natural bitumen (bituminous sands) deposits based on the borehole hydro-extraction technology. E3S Web of Conference. (123), 301036 https://doi.org/10.1051/e3sconf /201912301036

23. Pedchenko, M., \& Pedchenko, L. (2018). Expanding of spheres the application of borehole hydro-production technology to develop deposits of nontraditional hydrocarbons. E3S Web of Conference. (60), 00018. https://doi.org/10.1051/e3sconf/20186000018 